\title{
Ciência na cozinha: Discussões científicas ancoradas no cotidiano
}

\author{
Ciencia en la cocina: Discusiones científicas ancladas en el cotidiano
}

Science in the kitchen: Scientific discussions anchored in everyday life

\author{
Naiana Ribeiro Maximilla ${ }^{1}$ \\ Keila Reis Pereira ${ }^{2}$ \\ Lavínia Schwantes ${ }^{3}$
}

\begin{abstract}
Resumo
A educação nos anos iniciais do Ensino Fundamental, na educação infantil e na educação de jovens e adultos no Brasil acontece, quase que majoritariamente, pela atuação do profissional pedagogo. Dessa forma, tal profissional precisa aventura-se também pelo Ensino de Ciências. Sabendo que muitas vezes os cursos de Pedagogia oferecem poucas disciplinas acerca de fundamentos e metodologias dentro do tema, os cursos de extensão ainda na formação inicial desses profissionais podem ser muitos positivos para sua prática. Nesse contexto, o presente trabalho faz um relato sobre um curso de extensão oferecido para pedagogos em formação, no intuito de fornecer possibilidades para um ensino de ciências contextualizado. Objetivamos discutir e refletir acerca da necessária aproximação dos conteúdos científicos com cotidiano dos estudantes através da articulação do conhecimento científico com, no caso, a cultura. O tema do curso foi sobre culturas alimentares e sua articulação com alguns dos processos envolvidos no ato de alimentar-se e nutrir-se. A intenção de trabalhar ciências de forma contextualizada é para romper com o ensino transmissivo, que não foca na reflexão e na utilidade desse conhecimento na vida dos estudantes.
\end{abstract}

Palavras-Chave: pedagogia; ensino de ciências; culturas alimentares

\section{Resumen}

La educación en los años iniciales de la enseñanza fundamental, en la educación infantil y en la educación de jóvenes y adultos en Brasil ocurre, casi mayoritariamente, por la actuación del profesional pedagogo. De esta forma, tal profesional necesita aventurarse también por la Enseñanza de las Ciencias. Sabiendo que muchas veces los cursos de Pedagogía ofrecen pocas disciplinas acerca de fundamentos y metodologías dentro del tema, los cursos de extensión aún en la formación inicial de estos profesionales pueden ser muchos beneficiosos para su práctica. El presente trabajo hace un relato sobre un curso de extensión ofrecido para pedagogos en formación, con el fin de proporcionar posibilidades para una enseñanza de las ciencias contextualizadas. Tiene por objetivo discutir y reflexionar acerca de la necesaria aproximación de los contenidos científicos con cotidiano de los estudiantes a través de la articulación del conocimiento científico con, en el caso, la cultura. El tema del curso fue sobre cultivos alimentarios y su articulación con algunos de los procesos involucrados en el acto de alimentarse y nutrirse. La intención de trabajar ciencias de forma contextualizada es para romper la enseñanza transmisiva que no se enfoca en la reflexión y la utilidad de ese conocimiento en la vida de los Estudiantes.

Palabras claves: pedagogia; enseñanza de las ciências; culturas alimentares

\footnotetext{
${ }^{1}$ Graduada em Ciências Biológicas; Universidade Federal do Rio Grande - FURG; Rio Grande, Rio Grande do Sul, Brasil; naianamaximilla@ hotmail.com.

${ }^{2}$ Graduada em Ciências Biológicas Licenciatura; Universidade Federal do Rio Grande - FURG; Rio Grande, Rio Grande do Sul, Brasil; keila93pereira@ hotmail.com.

${ }^{3}$ Doutora em Educação em Ciências; Universidade Federal do Rio Grande - FURG; Rio Grande, Rio Grande do Sul, Brasil; laviniasch@gmail.com.
} 


\begin{abstract}
In Brazil, education in the elementary school (whether it is being provided to children, teens or even adults) is carried out mostly by pedagogues. This situation makes necessary for pedagogues to venture themselves in science teaching. Because pedagogy courses tend to offer few disciplines regarding the fundamentals and the methodologies of science, extension courses for future pedagogues, offered in the initial years of their formation, may have a very positive impact in their future professional performance. The present manuscript reports the offer of one such course to pedagogues in their formative years, aiming to open possibilities for a contextualized science teaching. The goal of the course was to discuss and reflect about ways to articulate cultural and scientific knowledge to provide the much needed approximation between the subjects in science curricula and the everyday reality of the students. The course thematics was food cultures and their relation with feeding behaviors and nutrition. Our ultimate goal in promoting the teaching of science in a contextualized manner is to break with transmissive teaching, which does not focus and on the utility of scientific knowledge in the lives of students.
\end{abstract}

Keywords: pedagogy, science teaching; food cultures

\title{
1. Introdução
}

O presente trabalho é resultado de um curso de extensão universitária oferecido no ano de 2016 ao curso de Pedagogia da Universidade Federal do Rio Grande, por discentes do curso de Ciências Biológicas - Licenciatura. O curso apresentava como objetivo contextualizar o conhecimento científico através de uma proposta diferenciada, debruçada em aspectos culturais relacionados à alimentação e não somente na transmissão de conceitos químicos, físicos e biológicos relacionados à nutrição.

De acordo com Diretrizes Curriculares Nacionais para o Curso de Pedagogia (DCNP), a educação nos anos iniciais do Ensino Fundamental, na educação infantil e na educação de jovens e adultos (EJA) acontece, quase que majoritariamente, pela atuação do profissional pedagogo (BRASIL, 2006). E parece desafiador enfrentar a diversidade de disciplinas/conteúdos que tais profissionais precisam trabalhar e a grande diversidade de estudantes com os quais se relacionam, variando em idade, situação social, para além das idiossincrasias relativas a cada um.

Somado à diversidade de estudantes que o pedagogo busca atender, existem inúmeras competências as quais esse profissional precisa exercer: é necessário capacitar esses professores para atuarem em diversas áreas do conhecimento, isto é, oferecer-lhes estratégias metodológicas para desenvolver e ministrar aulas, por exemplo, sobre temas de História, Geografia, Língua Portuguesa, Matemática e Ciências (BRASIL, 2013).

Apesar de o pedagogo atuar também como um professor de ciências, muitas vezes o currículo da sua graduação carece de disciplinas com carga horária suficiente para discussões aprofundadas sobre a área de ciências naturais e o ensino de ciências, o que posteriormente pode afetar o trabalho do professor em sala de aula; pois, como discute Schwartzman e Christophe (2009): "se o professor não tiver familiaridade e interesse pelas ciências e não 
souber motivar e estimular seus alunos torna-se difícil desenvolver uma educação em ciências de qualidade".

A partir dessa concepção, os cursos de extensão - ainda na formação inicial desses profissionais - podem ampliar as concepções científicas dos futuros pedagogos e aproximálos de discussões contemporâneas sobre temas variados dentro do ensino de ciências (JEZINE, 2004), sendo uma ótima ferramenta para aprimorar e estender o campo educativo desses profissionais, instrumentalizando-os para que utilizem metodologias diferenciadas, as quais objetivem englobar indivíduos pertencentes a diferentes realidades.

Os cursos de extensões, dentro da universidade, possibilitam a interdisciplinaridade e conexões entre diferentes áreas do conhecimento. Dentre seus objetivos, de acordo com Nogueira (2005, p. 51), podemos ressaltar:

\footnotetext{
a implementação do processo de democratização do conhecimento acadêmico, estabelecer mecanismos de integração entre os saberes acadêmico e popular, de forma que a produção do conhecimento se efetive no confronto com a realidade, com permanente interação entre teoria e prática. (NOGUEIRA, 2005, p.51)
}

Ao discutir a importância da articulação entre "teoria e prática" dentro do ensino de ciências, percebemos que a intenção de aproximar a ciência do cotidiano em espaços educativos não é recente. Muitos pesquisadores e documentos norteadores da área da educação sugerem tal aproximação. Nesse sentido, os cursos de extensão são uma ótima forma de aprimorar e estender o campo educativo desses profissionais, instrumentalizando-os para que utilizem metodologias diferenciadas, as quais objetivam englobar indivíduos pertencentes a essas diferentes realidades.

Chassot (2010) e Krasilchik (2007), ao falarem de um ensino de ciências que tencione a alfabetização científica do sujeito, frisam que o professor não pode apenas "transmitir" informação para os estudantes e que, por sua vez, esses não devem apenas "receber" aquelas informações de forma robótica. É necessário contextualizar, atribuir sentido àquilo que está sendo discutido. De acordo com o dicionário Houaiss, a contextualização é o processo de construção da inter-relação de circunstâncias que acompanham um fato ou uma situação, ou seja, em um determinado contexto, vários os aspectos bem como as articulações por eles estabelecidas, devem ser considerados.

A contextualização no ensino de ciências possibilita que o estudante-cidadão seja alfabetizado cientificamente, isto é, possibilita que ao concluir as etapas finais da educação básica, o mesmo tenha adquirido conhecimento e maturidade suficiente para além de 
compreender conceitos básicos da disciplina, sendo capaz de pensar independentemente, adquirir e avaliar informações, aplicando seus conhecimentos no cotidiano.

Delizaicov e Angotti (2000) reforçam a ideia supracitada, afirmando que "o ensinoaprendizagem de ciências deve nortear-se pela capacidade de instrumentalizar o aluno para melhor compreender a realidade onde se insere, possibilitando-lhe uma atuação consciente sobre ela". Independente de qual profissão o estudante pretenda exercer, aspectos relacionados às ciências os cercam cotidianamente; aspectos esses relacionados a questões políticas, sociais, ambientais e do cuidado de si.

Sendo assim, antes de pensarmos nos alunos da educação básica, primeiramente devemos pensar em preparar o professor-pedagogo para ser esse estudante-cidadão, socialmente e culturalmente situado. Como esperar, por exemplo, que os estudantes das séries iniciais do Ensino Fundamental sejam alfabetizados cientificamente, se na formação superior não preparamos seus professores para atuarem de tal forma?

Ao compartilharmos a experiência da criação e execução do presente curso de extensão, talvez consigamos alcançar outros profissionais e, dessa forma, propiciá-los a possibilidade de deslocar sua prática para "o lado" da contextualização do conhecimento científico trabalhado em aula, movimento esse que aproxima o estudante do seu cotidiano, tornando a aula um meio de discutir a realidade que nos cerca.

\section{Vivenciando a Ciência na cozinha: o curso de extensão}

O presente curso de extensão relatado foi divulgado com o título de "Ciência na Cozinha" e oferecido especificamente para uma turma do segundo ano da Pedagogia, da Universidade Federal do Rio Grande. A escolha do público alvo se deu pelo fato de que até o segundo ano da Pedagogia não há, na grade curricular, nenhuma disciplina sobre ciências. A proposta do curso em questão foi realizada pela primeira autora enquanto graduanda do curso de Ciências Biológicas da mesma universidade, em uma disciplina de estágio de docência obrigatório, orientada pela docente responsável pela disciplina.

A escolha do tema foi feita em conjunto com a turma da Pedagogia: muitas discentes sugeriram tópicos relacionados ao corpo e saúde. Devido à importância da alimentação na vida de todos nós, da primeira infância à terceira idade, o tema "alimentação e nutrição" possibilita discussão de diversos assuntos relacionados ao "corpo e saúde" de forma interdisciplinar e também pode ser abordado em qualquer nível de ensino (educação infantil, anos iniciais do Ensino Fundamental e EJA) pelo profissional pedagogo. 
Alicerçado nessa temática, o presente curso de extensão buscou aproximar as futuras professoras das ciências. Para isso, exploramos e discutimos sobre alguns aspectos culturais e biológicos da alimentação do ser humano. E, durante todo o tempo do curso, enfatizamos como o trabalhar ciências em sala de aula pode ser algo muito mais simples e prazeroso do que parece ser.

O curso de extensão foi realizado em quatro dias, no turno da noite. Em cada dia foi discutido um aspecto biológico, sempre relacionado a algum aspecto cultural envolvendo alimentação. A estratégia geral do curso foi sempre trabalhar a partir de algum artefato cultural ou a partir do conhecimento das próprias cursistas através de questionamentos. As atividades práticas também foram priorizadas, ocorrendo em todos os dias do curso e foram pensadas para serem prazerosas e úteis para as cursistas; mas que, principalmente, pudessem ser atividades realizadas por seus alunos, futuramente.

A seguir, descreveremos o desenvolvimento do curso da melhor forma possível ao leitor, mas de modo que não seja excessivamente detalhista; pois, a nossa intenção é difundir as ideias que sugiram no decorrer do planejamento, mas que poderão ser otimizadas e adaptadas a diferentes necessidades. Antes de tudo, é um relata de nossos esforços em construir um curso diferenciado, fomentando discussões sobre a importância de metodologias que tentam contextualizar o conhecimento científico, mas que não precisa e nem deve ser replicado com o rigor de um "protocolo". No Quadro 1, detalhamos os tópicos que foram abordados nos quatro dias de curso.

Quadro 1: Temáticas desenvolvidas no curso

\begin{tabular}{|l|l|}
\hline & Temática \\
\hline $\mathbf{1}^{\mathbf{0}}$ dia & $\begin{array}{l}\text { "Por que precisamos nos alimentar?"; "Alimentação e nutrição"; "Diversidade de Alimentos"; } \\
\text { "Cultura e hábitos alimentares"; "Atividades: Pirâmide alimentar e Rótulos de alimentos } \\
\text { industrializados". }\end{array}$ \\
\hline $\mathbf{2}^{\mathbf{0}}$ dia & $\begin{array}{l}\text { "Caminho dos alimentos no corpo"; "Doenças provocadas pela má alimentação/nutrição"; "Atividade: } \\
\text { Modelos didáticos - importância e construção". }\end{array}$ \\
\hline $\mathbf{3}^{\mathbf{0}}$ dia & "Sistema Nervoso e percepção/sentidos"; "Paladar"; "Olfato"; "Atividade: Cardápio dos Sentidos". \\
\hline $\mathbf{4}^{\mathbf{0}}$ dia & $\begin{array}{l}\text { "Sistema Nervoso e percepção/sentidos"; "Visão", "tato", "Audição"; "Atividade: Plano de aula de } \\
\text { ciências". }\end{array}$ \\
\hline
\end{tabular}

Fonte: A autora (2017)

No primeiro dia foram feitas as primeiras considerações sobre o tema culturas alimentares: alimentação e nutrição. Realizamos uma mesa com diferentes alimentos (frutas, industrializados, frituras, opções com carboidratos integrais, suco, café, água, refrigerante, etc.) para receber as inscritas, no intuito de parecer um "café informal". A partir dos alimentos selecionados por elas começamos a discutir aspectos relacionados à construção cultural do 
paladar tem papel importantíssimo na nossa preferência por determinados alimentos. Desde crianças nosso paladar é influenciado pela cultura familiar e pelos os círculos sociais aos quais pertencemos, e esses, por sua vez, são influenciados pela cultura regional e assim por diante.

Usando os exemplos que surgiam na aula - como o que cada um come, seus hábitos alimentares mais comuns, etc - discutimos sobre alimentos industrializados e sobre as questões culturais e sociais que nos fazem recorrer a esses alimentos (falta de tempo, integrantes da família trabalhando e/ou estudando), problematizando o consumismo e produção de lixo - tudo através do tema alimentação. Ainda no primeiro momento da aula, após a discussão inicial, utilizamos o gancho dos alimentos industrializados, para realizar a primeira atividade do dia: analisar a composição dos rótulos de alimentos congelados e processados. Em grupos, as estudantes da pedagogia deveriam analisar os rótulos que eram entregues, focando em componentes da fórmula que elas não conhecem. Dessa forma, se discutiu e se problematizou sobre a utilização e função dos diferentes aditivos químicos presentes nos alimentos industrializados.

Conforme os aditivos foram sendo identificados, fomos colando pequenos cartazes no quadro com as categorias mais comuns de aditivos: espessantes (aumentam a viscosidade dos alimentos), acidulantes (intensificam o gosto ácido dos alimentos), conservantes (inibem o crescimento microbiano), aromatizantes (alteram, adicionam ou intensificam aroma e sabor dos alimentos) e estabilizantes (mantém as propriedades físicas dos alimentos).

No segundo momento do primeiro dia de curso, trabalhamos os macronutrientes (carboidratos, lipídios, proteínas) através da construção de uma pirâmide alimentar com panfletos de ofertas de mercados locais. As cursistas recortavam alimentos presentes no panfleto e tentavam classificá-los como carboidratos, lipídios ou proteínas. $\mathrm{Na}$ base da pirâmide, representando a base da alimentação, deveriam colar os alimentos ricos em carboidratos: pães, tubérculos, raízes, cereais, massas. Na faixa intermediária da pirâmide deveriam conter os alimentos reguladores, aqueles essenciais ara o bom funcionamento do corpo: frutas e hortaliças. E no topo da pirâmide deveriam colar os alimentos proteicos, como carnes, ovos, leite e seus derivados.

No segundo dia, a partir de duas atividades práticas trabalhamos o tema: o caminho dos alimentos no corpo. A primeira atividade, chamada "Caminho do Sanduíche" consiste em alocar os estudantes em roda e distribuir placas com partes do corpo humano. Com o auxílio de um barbante ou fio qualquer, eles começam a criar o caminho que o "sanduíche" faz pelo corpo. Exemplo: o indivíduo com a placa que tem um estômago recebe uma ponta do fio, 
oferecido pelo indivíduo com a placa que tem a boca desenhada. Por sua vez, ele passa o barbante para o sujeito com a placa do intestino. O interessante dessa atividade, é que existem placas com partes do corpo além dos constituintes do sistema digestório, como o cérebro, as mãos, os olhos, o nariz, o coração, entre outros. Dessa forma, é possível realizar discussões sobre o "corpo" e não só sobre o "sistema digestório", mostrando que todos os constituintes do organismo participam de diversos processos, de forma interligada.

$\mathrm{Na}$ segunda atividade do segundo dia de curso, realizamos a "Aventura pelo corpo humano", que é uma forma ainda mais dinâmica de apresentar o caminho do alimento no corpo. Essa exposição interativa está localizada no Centro de Educação Ambiental, Ciências e Matemática (CEAMECIM-FURG) (Figura 1 e 2) e faz parte de um projeto de extensão que atende estudantes da rede de educação básica do município de Rio Grande. Nessa exposição estão alocados diversos modelos anatômicos e banners, distribuídos em um caminho em forma de labirinto. Em cada segmento da atividade temos algum órgão ou sistema representado em modelo anatômico e painéis com características do órgão e curiosidades; o caminho começa pela boca (entrada na estrutura/início da atividade) e termina no ânus (saída da estrutura/término da atividade).

Figura 1. Entrada da atividade 'Uma Aventura Pelo Corpo Humano'

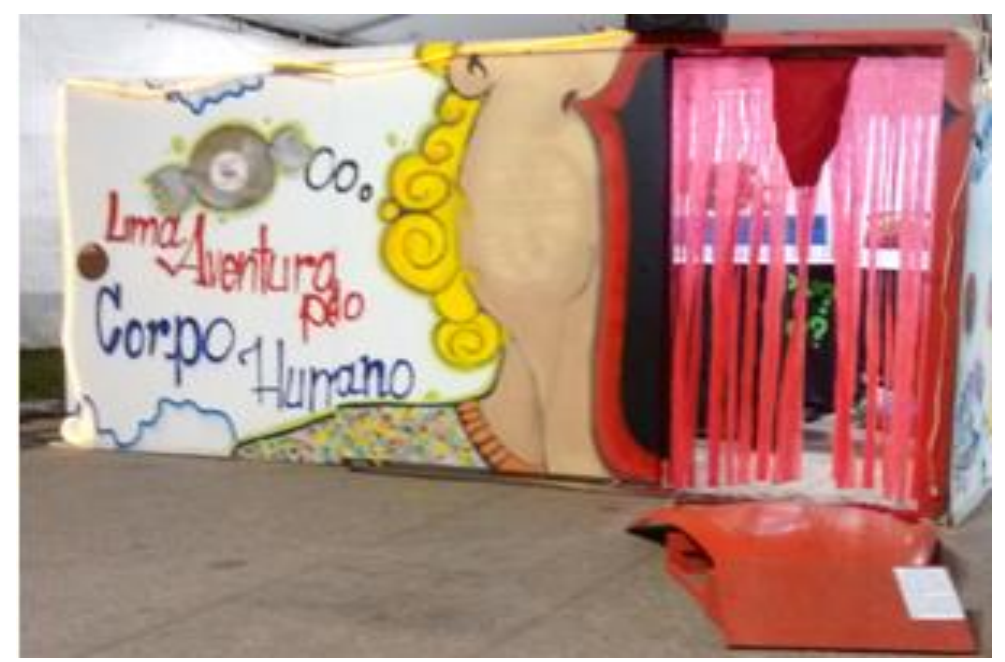

Fonte: Site CEAMECIM-FURG. 
Figura 2. Entrada da atividade 'Uma Aventura Pelo Corpo Humano'.

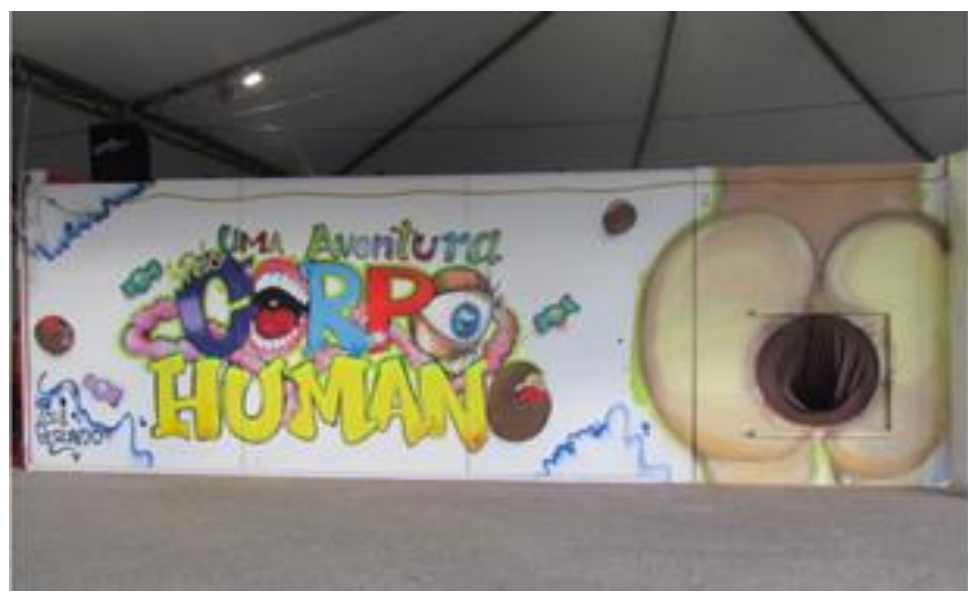

Fonte: Site CEAMECIM-FURG.

Nessa atividade discutimos a utilidade de modelos didáticos para facilitar o entendimento do conteúdo de ciências, incentivamos seu uso em sala de aula e traçamos alguns paralelos entre o que já havíamos discutido no dia anterior (primeiro dia do curso), reforçando a importância de retomar os conteúdos e relacioná-los entre si e com questões do cotidiano. Durante a atividade, muitos aspectos relacionados à saúde foram trazidos à tona e bastante discutidos, por iniciativa das estudantes. Exemplo: ao falarmos sobre o esôfago, surgiram perguntas sobre o porquê de sentirmos azia ou porquê de vomitarmos.

No terceiro e quarto dia as estudantes foram convidadas a utilizar os diferentes sentidos para discutir o tema alimentação, relacionando com o sistema nervoso. No terceiro dia começamos com a atividade intitulada "Cardápio dos Sentidos". Nessa atividade dividimos grupos responsáveis por cada sentido (olfato, paladar, audição, visão e tato) e uma cursista representante do sistema nervoso. Em uma sala, montamos uma mesa com diversos alimentos e cada grupo entrou na sala, separadamente, para tentar identificar os alimentos com o seu respectivo sentido; logo após, deveriam sair da sala e tentar repassar ao "sistema nervoso" suas impressões. O interessante foi trabalhar com a visão e audição, pois o fato de que o grupo da visão tinha obviamente mais facilidade para reconhecer os alimentos, nos fez discutir como priorizamos esse sentido no dia a dia, mas que no ato da alimentação não nos basta; e o grupo da audição, que ficou até um pouco relutante em entrar na sala, se surpreendeu quando identificou o som dos grãos de feijão na panela, por exemplo, e que nos permitiu discutir que esse sentido quase nunca é associado ao ato de alimentar-se, mas que também tem seu papel nesse processo. O "Cardápio dos Sentidos" foi uma ótima atividade para discutir os cinco sentidos de forma contextualizada através da alimentação; pois, todos os sentidos estão envolvidos no ato de obter alimento, por que então não relacioná-los? 
Normalmente ao falarmos de audição escolhemos exemplos característicos como a fala, canto dos pássaros, etc. Mas por que não falar do som da mastigação? Ou do som emitido quando estamos fritando algo? Ao final da atividade, começamos uma parte mais teórica do curso, apresentando, a partir de vídeos, o desenvolvimento embrionário e a organização dos sentidos e suas funções. A intenção dessa proposta era para que, a partir dos vídeos, as cursistas falassem o que mais as interessou ou questionamentos que surgiram no decorrer da reprodução dos mesmos. Nesse momento, muitas dúvidas foram surgindo e as discussões travadas a partir desses questionamentos, trouxeram muito dinamismo e utilidade prática à aula: dúvidas sobre o motivo biológico da surdez, mecanismos da fala, causa biológica da cegueira, amadurecimento visual de bebês e o motivo pelo qual as crianças são atraídas por objetos coloridos, dentre muitos outros.

Utilizamos também a atividade anterior, especificamente a parte em que os "sentidos" precisavam reportar ao "sistema nervoso" aquilo que eles presenciaram na sala, para discutirmos, nesses dois dias finais, os aspectos neurobiológicos relacionados aos sentidos. Algumas noções básicas sobre o que é um neurônio, partes constituintes do sistema nervoso e seu papel no processamento de informações e coordenação do organismo. E como todos os sentidos são, na verdade, uma extensão do sistema nervoso, de modo a permitir que o cérebro possa avaliar e responder ao nosso entorno.

No quarto e último dia, após terminar de discutir sobre os sentidos paladar e olfato, também trouxemos exemplos de diferentes artefatos culturais (reportagens, livros infantis, modelos anatômicos) que poderiam ser utilizadas pelas futuras pedagogas na elaboração de suas aulas, de forma a facilitar a contextualização do ensino de ciências, tão discutido durante o curso. Como atividade final, em aula, pedimos para que as estudantes criassem, em grupos, um breve plano de aula, considerando tudo que havíamos discutido no curso, e direcionando a aula para algum nível específico da educação (educação infantil, anos iniciais do ensino fundamental, EJA).

Para encerrarmos o curso e refletirmos sobre o ensino de ciências, lemos e discutimos o texto de Pavão (2014), intitulado "Ensinar ciências fazendo ciência, por uma revolução pedagógica", onde o autor discute sobre como trabalhar ciências na escola, sugerindo-nos que nos afastemos do ensino científico positivista, onde repassamos protocolos a serem replicados pelos estudantes, e nos convida a fazer uma ciência diferente, utilizando:

Procedimentos próprios da Ciência como observar, formular hipóteses, experimentar, registrar, sistematizar, analisar, criar [...] defendendo a ideia de que as crianças desde as séries iniciais possam vivenciar tais procedimentos, sendo então 
estudantes-pesquisadores. [...] as crianças são naturalmente curiosas, sabem formular boas perguntas e gostam de atividades práticas. (PAVÃO, 2014)

Ao final do curso, elaboramos e disponibilizamos na forma digital para as cursitas, uma cartilha com todas as atividades, materiais e sugestões utilizados para a articulação entre a ciência e a cozinha.

\section{Resultados e discussão}

O retorno obtido com o curso foi muito positivo. As discentes acompanharam e se interessaram por todas as discussões realizadas e participaram de todas as atividades propostas. Todas mostraram entusiasmo pela abordagem usada no curso, principalmente em relação às atividades práticas. Muitas vezes somos levados a crer que apenas atividades de laboratório são possíveis e desejadas no ensino de ciências, mas muitas atividades práticas e lúdicas, de baixo custo, podem ser realizadas se pesquisarmos a melhor forma de abordar o tema. Como destaca Moraes (1995): “o ensino de Ciências não exige equipamentos sofisticados nem requer que o professor conheça as respostas de todas as questões que propõe aos alunos. Exige, entretanto, disposição para aprender com estes".

No nosso curso, todas as atividades realizadas se enquadram no conceito de lúdico que, de forma resumida, podemos definir como atividades educativas práticas que priorizam o divertimento dos envolvidos, trabalhando, muitas vezes, os conceitos teóricos discutidos em sala de aula. A incorporação de brincadeiras, de jogos e de brinquedos na prática pedagógica desenvolve diferentes capacidades que contribuem com a aprendizagem, ampliando a rede de significados construtivos tanto para as crianças, como para os jovens e adultos (MALUF, 2006). Como alguns exemplos de atividades lúdicas realizadas no curso, podemos retomar: a atividade de análise de rótulos de alimentos industrializados, o "cardápio dos sentidos", “o caminho do sanduíche" e até mesmo a "Aventura pelo corpo humano" - apesar da última ser uma construção que demandou financiamento, com algum esforço, pode ser uma atividade adaptada por escolas, por exemplo.

No último dia, anonimamente, elas realizaram a atividade destinada à avaliação do curso, na forma escrita. Ao ler as avaliações, nos deparamos com alguns relatos que diziam que o curso "proporcionou descobertas, reflexões sobre o tema e como trabalhar ciências em sala de aula". Algumas estudantes também relataram que o curso de Pedagogia tem várias disciplinas que trabalham muito o lúdico, mas que havia poucas articulações com o Ensino de Ciências, e que o curso pode contribuir muito aspecto. No Quadro 2, trouxemos mais alguns desses relatos na íntegra: 
Quadro 2: Relatos das cursistas

\begin{tabular}{l}
\hline "O curso fez com que eu ampliasse os conhecimentos sobre ciências, relembrando \\
assuntos discutidos no Ensino Médio. Fez com que eu pensasse em como aplicar \\
atividades na Ed. Infantil/Anos iniciais." \\
\hline 2 "Aprendi muito e vivenciei dinâmicas que irão nortear meu trabalho de \\
educadora." \\
\hline 3 "Achei interessante as dinâmicas, pois todos puderam participar e dessa forma \\
aprender os conteúdos de forma interativa."
\end{tabular}

Fonte: A autora (2017)

Com os planos realizados ainda em aula, conseguimos perceber que atingimos o objetivo proposto pelo curso. As estudantes conseguiram colocar elementos nesses planos que contextualizaram e tentaram aproximar as ciências do cotidiano. Um dos planos, por exemplo, utilizou a história da "Raposa e as Uvas" para discutir a importância da alimentação e da sua relação com o exercício físico; outro plano apresentou uma proposta para trabalhar a importância da alimentação junto ao cuidado e higienização da boca e dentes - ambos os trabalhos foram direcionados à educação infantil. Segundo Kato e Kawasaki (2011):

Contextualizar é trazer a realidade do aluno não apenas como ponto de partida para o ensino, mas como o próprio contexto de ensino. Assim, trazer os contextos de vivência dos alunos para os contextos de aprendizagem torna-se um importante fator de aprendizagem, pois dá sentido aos conhecimentos aprendidos. Ao professor, cabe o papel de apresentar, aos estudantes, uma forma de ler, interpretar e intervir neste conjunto de vivências e no mundo em que vivem (KATO e KAWASAKI, 2011).

As contextualizações feitas durante o curso, trouxeram questões sobre 1) saúde: ao trabalharmos o caminho do alimento no corpo, muitas dúvidas em relação aos órgãos e seu funcionamento normal e patológico foram discutidas; 2) Cultura: ao considerarmos a dieta de cada um durante as discussões, as questões culturais no preparo e preferência por alimentos, como também problematizamos o consumo excessivo de alimentos industrializados e a necessidade de recorrer a esses alimentos; 3) O papel dos sentidos durante a alimentação: quando falamos em comer, normalmente só pensamos no olfato e paladar. Mas o tato, audição e visão também participam desse processo. Quem nunca salivou ao ver um outdoor com a imagem de um alimento atrativo, ao passar de carro ou ônibus, justamente no momento que estava com fome? São detalhes, questões simples, mas que podem atribuir maior coerência ao trabalharmos determinado assunto.

Durante todo o decorrer do curso, frisamos que para propor e realizar um trabalho diferenciado é necessário organização, pesquisa e esforço para colocar as ideias em prática. Perguntávamos sempre: "quanto tempo vocês acham que levamos para organizar tais 
atividades?". Se não dispusermos de tempo para pensar e organizar nossas propostas, isso dificultará nossa tentativa de elaborar trabalhos atrativos para os alunos.

Para concluir esse tópico, é importante ressaltar que o curso foi dinâmico, divertido e muito prazeroso: resultado da colaboração de todos durante as discussões e atividades. Houve troca mútua de conhecimentos entre os participantes e proponentes do curso, mostrando que o espaço para questionamentos e reflexões deve ser priorizado nas dinâmicas de aula, para construirmos conjuntamente o conhecimento.

\section{Considerações finais}

Como já discutido anteriormente, é de extrema importância a atuação do profissional pedagogo para a educação brasileira, por ser esse o profissional capacitado a atuar nos primeiros níveis da educação básica.

Visto que muitas vezes no decorrer das disciplinas da graduação em pedagogia pode faltar tempo para discutir com os discentes tópicos de forma aprofundada, os cursos de extensão oferecidos dentro da universidade podem beneficiar esses estudantes ao propiciar discussões e atividades que enriquecerão seu embasamento teórico e a diversificação de suas práticas. Seria muito útil para a atuação desses profissionais se os diferentes departamentos dentro da universidade oferecessem cursos de extensão visando exclusivamente esse público alvo, como por exemplo: os institutos de matemática, letras, computação, biologia, física, etc.

É importante ressaltar que, na grande maioria das vezes, os cursos de extensão destinados aos profissionais da docência, são oferecidos para professores já atuantes, no modo de formação continuada. Oferecer a possibilidade de aperfeiçoamento para professores ainda na formação inicial só aumenta as chances de formar profissionais capacitados, precisando de menos "remediações" posteriores.

Como nos mostra a Lei de Diretrizes e Bases da Educação, a formação básica do cidadão depende, dentre outros fatores, da "compreensão do ambiente natural e social, do sistema político, da tecnologia, das artes e dos valores em que se fundamenta a sociedade" (Art. 32 inciso II). Dessa forma, contextualizar o conhecimento científico é passo crucial para tornar as aulas de ciências úteis aos alunos e possibilitar que esse cidadão seja atuante nos diversos setores da nossa sociedade, as quais necessitem desse letramento científico.

Como professores, independente da formação específica, devemos sempre almejar que aquilo trabalhado em sala de aula extrapole os muros da instituição e chegue à comunidade, causando reflexões, articulações, identificação e soluções de problemas vigentes. Não 
podemos somente visar a nota do estudante no final do período letivo: o percurso rico e reflexivo é o que deve ser incentivado.

Por fim, o presente curso relatado foi bem recebido pelas discentes da pedagogia, mostrando que não só é possível como também necessário realizar essas articulações entre as áreas de conhecimento, compartilhando os saberes referentes a cada uma dessas áreas e contextualizando o conhecimento de forma interdisciplinar.

\section{Referências}

BRASIL, Lei de Diretrizes e B. Lei no 9.394/96, de 20 de dezembro de 1996. Disponível em: http://www.planalto.gov.br/ccivil_03/leis/L9394.htm. Acesso em: 29 setembro 2017.

Ministério da Educação. Resolução CNE/CP no 1, de 15 de maio de 2006. Institui Diretrizes Curriculares Nacionais para o curso de graduação em Pedagogia, licenciatura. Diário Oficial da União, Brasília, 16 maio 2006. Seção I, p. 11. Disponível em: http://portal.mec.gov.br/cne/arquivos/pdf/rcp01_06.pdf . Acesso em: 30 setembro 2017.

. Ministério da Educação. Conselho Nacional de Educação. Câmara De Educação Básica. Diretrizes Curriculares Nacionais da Educação Básica. Disponível em: http://portal.mec.gov.br/index.php?option=com_docman\&view=download\&alias=15548-d-cn-educacao-basica-nova-pdf\&Itemid=30192. Acesso em: 30 setembro 2017.

CHASSOT, A. Alfabetização científica: questões e desafios para a educação. Ijuí: Ed. Unijuí. 2010.

DELIZOICOV, D.; ANGOTTI, J. A. Metodologia do ensino de Ciências. São Paulo: Cortez. 2000.

HOUAISS, A.; VILLAR, M. S. Minidicionário Houaiss da língua portuguesa. Instituto Antônio Houaiss de Lexicografia e Banco de Dados da Língua Portuguesa. Rio de Janeiro: Objetiva, 2001.

JEZINE, E. As Práticas Curriculares e a Extensão Universitária. In: CONGRESSO BRASILEIRO DE EXTENSÃO UNIVERSITÁRIA, 2. Anais do... Belo Horizonte, 2004. Disponível em: https://www.ufmg.br/congrext/Gestao/Gestao12.pdf. Acesso em: 20 de outubro de 2017.

KATO, D.S.; KAWASAKI, C.S. As concepções de contextualização do ensino em documentos curriculares oficiais e de professores de ciências. Ciência \& Educação, v. 17, n. 1, p. 35-50, 2011.

KRASILCHIK, M., MARANDINO, M. Ensino de Ciências e Cidadania. 2a ed. São Paulo: Editora Moderna. 2007, 87p.

MALUF, A.C.M. Atividades lúdicas como estratégias de ensino aprendizagem. 2006. Disponível em: http://www.psicopedagogia.com.br/artigos/artigo.asp?entrID=850. Acesso em: 29 setembro 2017. 
MORAIS, Roque. Ciências para as Séries Iniciais e alfabetização. Porto Alegre: Sagra DC Luzzatto, 1995.

NOGUEIRA, M. (Org.). Extensão universitária: diretrizes conceituais e políticas. Belo Horizonte: UFMG, 2000.

PAVÃO, A. C. Ensinar ciências fazendo ciência, por uma revolução pedagógica. In:

RIBEIRO, P. R. C.; MAGALHÃES, J. C. (orgs). Ensinando Ciências: outros olhares e outras possibilidades. Rio Grande: FURG. 2014. 208p.

SCHWARTZMAN, S.; CHRISTOPHE, M. A educação em ciências no Brasil, 2009.

Disponível: http://www.schwartzman.org.br/simon/2009_11_abciencias.pdf. Acesso em: 30 setembro 2017.

Site CEAMECIM-FURG. Disponível em: http://www.ceamecim.furg.br/index.php. Acesso em 29 setembro 2017. 